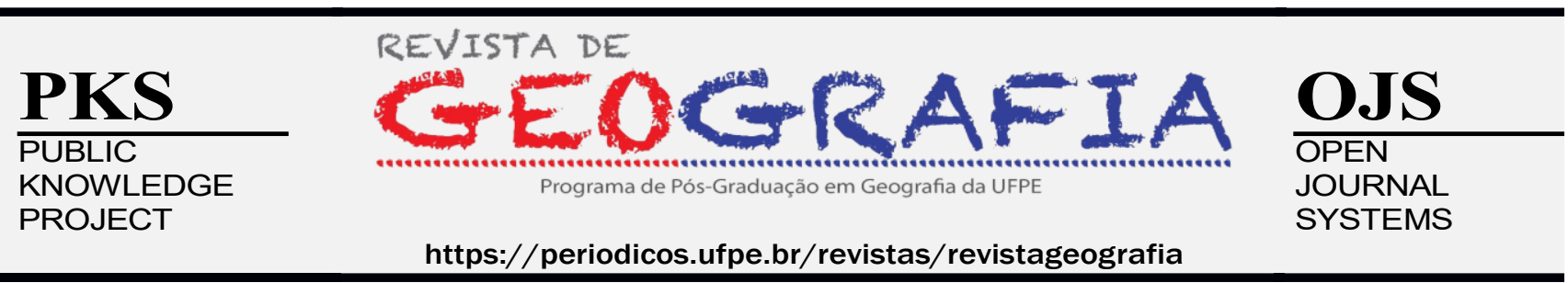

\title{
OS EVENTOS EXTREMOS EM JUIZ DE FORA -MG: INVESTIGAÇÃO A PARTIR DA TÉCNICA DOS MÁXIMOS DE PRECIPITAÇÃO
}

\author{
Thiago Alves de Oliveira ${ }^{1}$, Cássia de Castro Martins Ferreira ${ }^{2}$
}

\begin{abstract}
${ }^{1}$ Universidade de São Paulo (USP). E-mail: thiago.a.oliveira@usp.br, Orcid: https://orcid.org/0000-0002-75202251

${ }^{2}$ Universidade Federal de Juiz de Fora (UFJF).E-mail: cassia.castro@ufjf.edu.br, Orcid: https://orcid.org/00000002-6070-7257
\end{abstract}

Artigo recebido em 18/02/2021 e aceito em 19/05/2021

\section{RESUMO}

Os eventos extremos são assim considerados, em função de seu afastamento das condições habituais e por ocorrerem com uma baixa frequência, porém com elevada capacidade de causar danos à sociedade. Com isso, o objetivo desse trabalho é categorizar os eventos de precipitação na cidade de Juiz de Fora e entender a circulação atmosférica associada aos eventos extremos de precipitação classificados como mais intensos (Intensidade IV). Para a identificação dos eventos extremos procedeu-se com a técnica dos máximos de precipitação, sendo possível avaliar os eventos a partir de classes de intensidade. A partir disso procedeu-se uma investigação episódica dos eventos de maior magnitude (intensidade IV) de acordo com a sua gênese, e os impactos na cidade. Com relação aos resultados, observou-se que todos os eventos ocorreram no período da estação chuvosa, entre Outubro e Março, sendo que a classe de intensidade IV é caracterizada por totais pluviométricos superiores a $114,2 \mathrm{~mm} / 24 \mathrm{~h}$. Foram identificadas 5 datas em que os totais pluviométricos superaram essa marca. Foi possível observar que todos os eventos estiveram associados à passagem de Sistemas Frontais que levam à convergência de umidade da região Amazônica, principalmente no período do verão.

Palavras- chave: Impactos das chuvas; Frentes frias; Sistemas atmosféricos; Zona de Convergência do Atlântico Sul.

\section{EXTREME EVENTS IN JUIZ DE FORA -MG: INVESTIGATION FROM THE PRECIPITATION MAXIMUM TECHNIQUE}

\begin{abstract}
Extreme events are thus considered, due to their distance from usual conditions and because they occur with a low frequency, but with a high capacity to cause damage to society. Thus, the objective of this work is to categorize precipitation events in the city of Juiz de Fora and understand the atmospheric circulation associated with extreme precipitation events classified as more intense (Intensity IV). For the identification of the extreme
\end{abstract}


events proceeded with the technique of the maximum of precipitation, being possible to evaluate the events from intensity classes. From this we proceeded an episodic investigation of the events of greater magnitude (intensity IV) according to their genesis, and the impacts on the city. Regarding the results, it was observed that all events occurred during the rainy season, between October and March, and intensity class IV is characterized by rainfall totals greater than $114.2 \mathrm{~mm} / 24 \mathrm{~h}$. Five dates were identified when total rainfall exceeded this mark. It was possible to observe that all events were associated with the passage of frontal systems that lead to the convergence of humidity in the Amazon region, especially in the summer period.

Key-words: Rain impacts, Atmospheric Systems, Cold Fronts, South Atlantic Convergence Zone

\title{
INTRODUÇÃO
}

Os eventos extremos são assim considerados em função de seu afastamento das condições habituais e por ocorrerem com uma baixa frequência, porém com elevada capacidade de causar danos à sociedade (GONÇALVES, 1992; VICENTE, 2005; STHEPHENSON, 2009; PINHEIRO, 2016; MONTEIRO, 2016; GOUDARD, 2019).

Segundo Monteiro (1991), "encontram-se entre os mais importantes, seja pela complexidade e diversidade de fenômenos quanto pela frequência e variação de intensidade dos impactos causados" (MONTEIRO, 1991, p. 8), dito isso, algumas características serão fundamentais na investigação dos extremos: sua frequência e intensidade (GOUDARD, 2019). A frequência e a intensidade dos eventos extremos estarão associadas às relações estabelecidas pelos sistemas atmosféricos nas diversas escalas do clima.

Monteiro (1999) chamando a atenção para os problemas das escalas geográficas do clima, assevera que

\begin{abstract}
Quando enunciamos o clima de um lugar (espaço) é a resultante do comportamento dinâmico mais habitual ou recorrente da atmosfera, cronologicamente desenvolvido (tempo) sobre aquele dado lugar, teremos que definir que lugar é este. Ele pode variar desde o globo terrestre, passando pelos continentes, regiões países até atingir um dado lugar (ponto) que pode ser uma pequena ilha, uma grande, média ou pequena cidade que por sua vez, poderá ser subdividida em bairros, setores, ruas, etc. (MONTEIRO, 1999, p.10).
\end{abstract}

Nesse sentido, os eventos extremos irão representar os desvios em relação aos padrões de circulação atmosférica habituais, desse modo, os impactos meteóricos serão variáveis ao redor da terra em função das dinâmicas climáticas locais. Para Monteiro (1976)

\footnotetext{
A ideia de impacto implica em consequências calamitosas, atacando a integridade da cidade como artefato físico e perturbando sensivelmente as formas de circulação e comunicação internas e de ligação externa. São episódios ou eventos restritos no tempo que estão presos ao modo de transmissão de energia, ou seja, ao ritmo de sucessão dos estados atmosféricos (MONTEIRO, 1976, p. 171).
}

Os estudos acerca dos eventos extremos devem estar associados à investigação da gênese dos eventos, bem como as possibilidades e os mecanismos de defesa (MONTEIRO, 1976). No sudeste do Brasil, como exemplifica Monteiro (1999), algumas configurações atmosféricas associadas à 
dinâmica das frentes frias ocasionam e provocam a ocorrência dos aguaceiros intensos, principalmente na primavera e no verão.

Diversas são as parametrizações para os eventos extremos pluviométricos, por vezes podem ser caracterizados a partir de valores estabelecidos, como Gonçalves $(1992,2003)$ com 60mm para a cidade de Salvador- BA, e Zanella (2006) que aplicou os 40mm para a cidade de Curitiba-PR.

Além disso, diversas técnicas estatísticas podem ser empregadas para a identificação dos eventos extremos, dentre elas despontam a utilização dos percentis 95 e 99 (LOUREIRO, 2014; PRISTO et al, 2018; GOUDARD, 2019; PAZ et al, 2019), dos quantis (MONTEIRO, 2016; WANDERLEI et al, 2018), a técnica do decil (CAMPOS et al, 2015) às técnicas dos máximos de precipitação (MONTEIRO e ZANELLA, 2017; 2019), além dos índices de extremos climáticos do ETCCDI (PINHEIRO, 2016; VALVERDE, 2018; MARENGO et al, 2020).

Monteiro e Zanella (2017) utilizaram a técnica dos máximos de precipitação aplicada aos municípios de Fortaleza, Sobral e Crato, destacam que a técnica "permitiu definir um limiar de chuva para caracterizar diferentes níveis de eventos extremos nas localidades supracitadas, além de permitir a identificação do número de episódios de grande magnitude” (MONTEIRO e ZANELLA, 2017, p. 137). Monteiro e Zanella (2019) utilizaram a técnica dos máximos de precipitação para investigar a gênese dos eventos extremos no estado do Ceará, ocorridos em março de 2019.

O presente trabalho objetiva categorizar os eventos de precipitação na cidade de Juiz de Fora a partir da técnica estatística dos máximos de precipitação, e entender a circulação atmosférica associada aos eventos extremos de precipitação classificados como mais intensos (Intensidade IV).

\section{CARACTERIZAÇÃo DA ÁREA DE ESTUDO}

Do ponto de vista Zonal observa-se que a faixa intertropical é marcada por intensa recepção de radiação solar incidente, além de elevados totais pluviométricos, Nimer (1979) ao discutir a climatologia da Região Sudeste do Brasil destaca que as "latitudes médias são submetidas a um ciclo de estações que, embora suas características estejam sujeitas à variabilidade de intensidade, podemos dizer que é regular e bem definido" (NIMER, 1979, p. 265).

A posição zonal da região Sudeste, com terras cortadas pelo trópico de Capricórnio denotam um caráter transicional, o que caracteriza "uma faixa de conflito entre sistemas tropicais e extratropicais, sendo que seus mecanismos de circulação estão sob o controle da dinâmica da frente polar" (NUNES et al, 2009, p. 245). 
Em alguns estudos mostram que no setor central da América do Sul observa-se uma circulação atmosférica de monção, pois $80 \%$ dos totais pluviométricos anuais se concentram em um período de 6 meses, dessa forma, Juiz de Fora (Figura 01 e 02) se colocaria nesse contexto (GAN et al, 2009; REBOITA et al, 2012, 2015).

Figura 01- Localização do município de Juiz de Fora

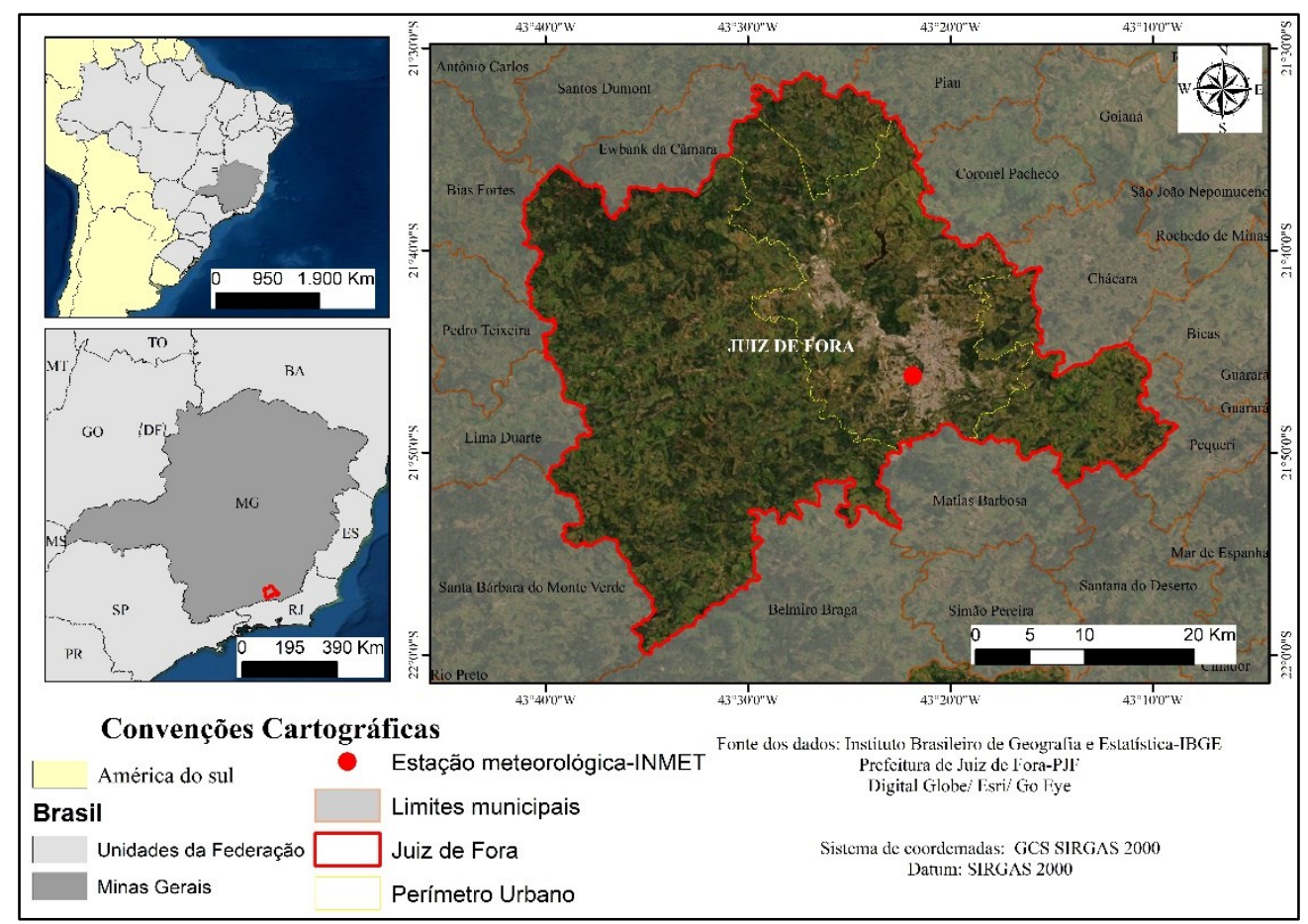

Fonte: Organizado pelos autores.

Figura 02- Médias pluviométricas mensais - 1910-2018

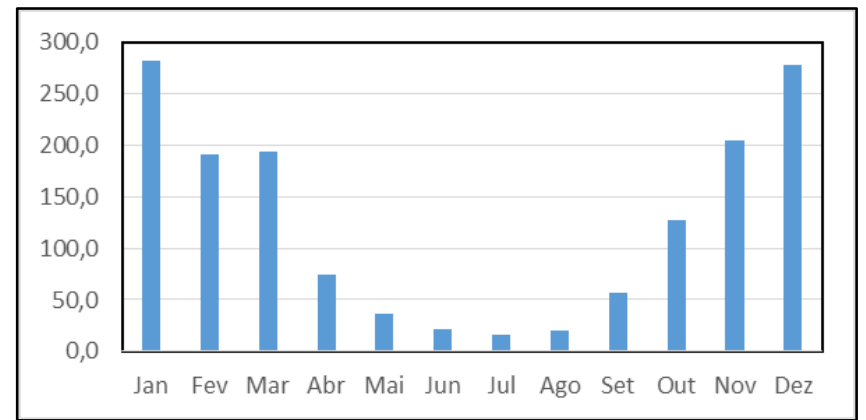

Fonte: Organizado pelos autores.

O sistema de monção da América do Sul se desenvolve durante a primavera "com o aumento da convecção sobre o noroeste da bacia Amazônica, em meados de setembro, quando avança para o Sudeste, até atingir a longitude de $48^{\circ} \mathrm{W}$ (região Sudeste do Brasil) em novembro" (GAN et al, 2009, 
p. 298), esse deslocamento engendra a estação chuvosa, caracterizada pelos elevados totais pluviométricos.

No período de verão, com o aumento da temperatura no continente Sul Americano os sistemas quentes e úmidos equatoriais migram para sul, abastecendo de umidade os setores mais austrais, assim, "o transporte de umidade do oceano Atlântico, associado à sua reciclagem sobre a floresta tropical, mantém a precipitação máxima sobre o Brasil Central, favorecendo a formação da Zona de Convergência do Atlântico Sul (ZCAS)" (GAN et al, 2009, p. 298).

Dentre os principais sistemas atmosféricos atuantes no período do verão, deve-se destacar a Zona de Convergência do Atlântico Sul (ZCAS) principal fonte de umidade para o Sudeste do Brasil, oriunda da região Amazônica. Autores como Borsato (2016) a definem como "uma faixa de intensa nebulosidade se estende de noroeste a sudeste desde a Amazônia até o interior do Atlântico Sul” Borsato (2016, p. 140). Esse sistema atmosférico está associado a eventos de precipitação diária intensa e caracterizados pelos eventos extremos de precipitação (CAVALCANTI, 2012). Quando a convergência de Umidade perdura por um período menor que três dias, considera-se como Zona de Convergência de Umidade (ZCOU), quando ultrapassa os três dias a designação passa a ser Zona de Convergência do Atlântico Sul (ZCAS) (BORSATO, 2016).

Um elemento fundamental para a configuração de uma Zona de Convergência do Atlântico Sul é a atuação dos Jatos de Baixos Níveis (JBN), tendo como origem o Anticiclone Semifixo do Atlântico Sul (ASAS), adentram na região Norte do Brasil interagem com a Floresta Amazônica e ao se deparar com os Andes são direcionados a leste da Cordilheira, quando associados a sistemas frontais no Sudeste do Brasil, podem dar o "start" para a formação de uma convergência de umidade e posteriormente a formação de uma Zona de Convergência do Atlântico Sul (ZCAS), (REBOITA et al, 2012).

No caminhar do outono para o inverno, os sistemas convectivos migram para Norte, em função das diferenças e temperatura e o deslocamento da Zona de Convergência Intertropical (ZCIT) dessa forma "o transporte de umidade em baixos níveis, proveniente do oeste da Amazônia, enfraquece devido às frequentes incursões de ar seco e frio proveniente das latitudes médias sobre o interior da região subtropical da América do sul" (GAN et al, 2009, p. 298). E outra condição sinótica passa a atuar no contexto do sudeste do Brasil, marcado pela entrada das Frentes Frias ocasionadas pelo deslocamento do Anticiclone Polar, formando a Massa Polar Atlântica, além do deslocamento do Anticiclone Semifixo do Atlântico Sul (ASAS) em direção ao continente, formando a Massa 
Tropical Atlântica, denotando tipos de tempo em condições de estabilidade e, consequentemente, com baixos totais pluviométricos.

\section{A cidade de Juiz de Fora}

A cidade de Juiz de Fora seguiu o ritmo da urbanização brasileira, com um processo intenso na segunda metade do século XX, marcado pela elevação na população total do município, bem como o crescimento da população urbana, que atingiu 92\% na década de 1970 (PJF, 2020) influenciando assim para o crescimento da mancha urbana, figura 03, sendo que em 1950 a área urbana era de 19,3 $\mathrm{Km}^{2}$, chegando a 130,8 $\mathrm{Km}^{2}$ em 2010, quando a população urbana atingiu 98,9\% (PJF, 2020).

Figura 03- Evolução da população e da mancha urbana de Juiz de Fora- MG

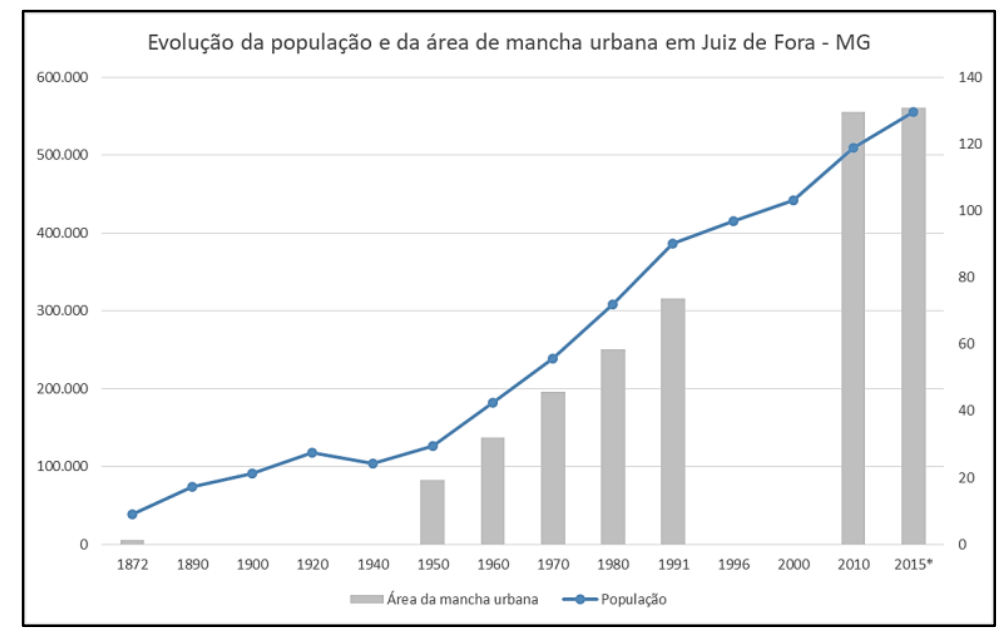

Fonte dos dados: IBGE; Prefeitura de Juiz de Fora-PJF. Organizado pelo autor.

A mancha urbana de Juiz de Fora se desenvolveu a princípio no centro da cidade e às margens do Rio Paraibuna, principalmente a partir da estrada nova do Halfeld, além disso a instalação da ferrovia no mesmo eixo (Figura 04), fez com que se desenvolvesse essa ocupação marginal, ao rio, a estrada e a linha férrea (SOUZA, 2016; GERALDO, 2014).

Segundo Geraldo (2014), a partir da década de 1980 "houve a tendência à concentração de equipamentos atrativos nas regiões noroeste e sudoeste da cidade. $\mathrm{O}$ fator de maior evidência é a presença da BR-040 e recentemente dos acessos Norte e Sul, compondo o Cinturão da BR-040" (GERALDO, 2014, p. 123). A região Oeste da cidade, conhecida como cidade alta, apesar de ter uma ocupação antiga (associada a imigração alemã), foi a partir da década de 1980 que esta região teve um crescimento elevado (GERALDO, 2014). De acordo com Rodrigues (2005) as regiões Oeste e 
Noroeste representaram no período de 1991 a 2000 os maiores incrementos populacionais do município.

Figura 04- Evolução da mancha urbana em Juiz de Fora de 1963 a 2010.

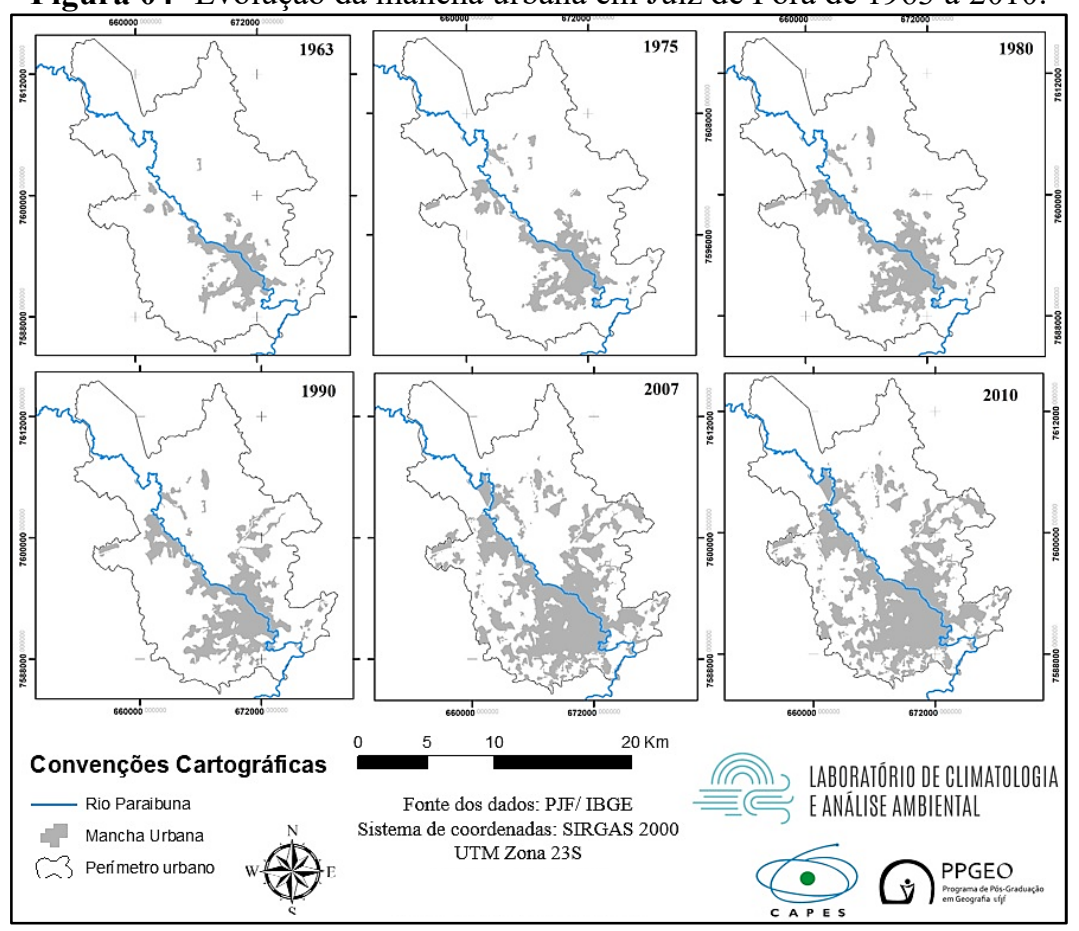

Fonte: Organizado pelo autor.

\section{MATERIAIS E MÉTODOS}

Os procedimentos metodológicos se dividiram em uma primeira etapa de levantamento de dados pluviométricos, cartas sinóticas, imagens de satélite e de informações sobre os impactos das chuvas na cidade, e na segunda parte foi aplicada a técnica estatística dos máximos de precipitação, para a investigação dos extremos pluviométricos. Esses procedimentos serão detalhados a seguir.

\section{Levantamento de dados}

Os dados de precipitação diária no município de Juiz de Fora-MG no período de 1980-2018 foram coletados na estação meteorológica do INMET (Código 83692), localizada no Campus da Universidade Federal de Juiz de Fora-MG (Figura 01). O levantamento dos dados foi realizado junto ao Laboratório de Climatologia e Análise Ambiental - LabCAA, sendo que os dados apresentavam falhas de registro nos seguintes dias (Tabela 01): 
TABELA 01-Período com falhas na série de dados

\begin{tabular}{c|c}
\hline Ano & Falhas na série \\
\hline 1991 & Mar., Abr. (Mês todo) \\
\hline 1992 & Mar., Abr., Mai, Jun., Jul. (Mês todo) \\
\hline 1997 & Ago. Set. Out. Nov., Dez. (Mês todo) \\
\hline \multicolumn{2}{c}{ Fonte: Organizado pelos autores. }
\end{tabular}

Comparando dos dados faltantes na estação do INMET, utilizada no presente trabalho, em outros dois postos pluviométricos da ANA localizados no município, o posto de Torreões (02143016) e Chapéu D’Uvas (02143020), localizados a 23 e 28km, respectivamente, da estação do INMET. No ponto de Torreões foi identificado apenas um evento de 60mm em Dezembro de 1997 e no ponto de Chapéu D’Uvas nenhum evento superior ao percentil 95 foi registrado nesses meses, dessa forma os períodos faltantes pouco influenciaram nos resultados encontrados.

Para a identificação dos sistemas atmosféricos foram utilizadas as cartas sinóticas disponibilizadas pela Marinha do Brasil, (https://www.marinha.mil.br/chm/dados-do-smm-cartassinoticas/cartas-sinoticas), além disso para auxiliar a interpretação dos sistemas atmosféricos foram utilizados os dados CHIRPS, estes são estimados a partir de imagens de radar meteorológico e ajustados a partir de estações de superfície, conforme descrevem Funk et al (2015), disponibilizados pela Universidade da Califórnia, Santa Bárbara-USA (https://www.chc.ucsb.edu/data/chirps/).

Estes dados são disponibilizados em formato .tiff, iniciando-se a partir de $1981 \mathrm{em}$ uma escala de tempo diária, pentadal (conjunto de 5 dias), decendial (período de 10 dias), além dos dados mensais e anuais, foram utilizados os dados pentadais que congregassem o dia do evento analisado, por representarem uma maior confiabilidade da estimativa, conforme destacam Silva et al (2019).

As notícias de jornal foram coletadas junto ao arquivo histórico da Prefeitura de Juiz de Fora, sendo que foram consultados os jornais Tribuna de Minas, disponíveis para acesso público na Biblioteca Municipal Murilo Mendes.

\section{A técnica dos máximos de precipitação}

A técnica dos máximos de precipitação, aplicada por Monteiro (2016) e Monteiro e Zanella (2017), avalia e identifica os eventos extremos de precipitação a partir de classes de intensidade, "tal metodologia apresenta mais coerência no tratamento de eventos extremos de chuva, uma vez que trabalha com um limiar de chuva e classes de intensidade de chuva” (MONTEIRO, 2016, p. 70). 
Para a aplicação da técnica, Monteiro e Zanella (2017) selecionaram todos os eventos pluviométricos iguais e superiores a $50 \mathrm{~mm} / 24 \mathrm{~h}$, após esse levantamento foram extraídas duas medidas de tendência central para esses dados, a média e o desvio padrão. No presente estudo, o valor de $50 \mathrm{~mm}$ foi substituído pelo valor do percentil 95, extraído a partir da série de dados de Juiz de ForaMG. O valor do percentil 95 calculado foi de 45,6 mm. Posteriormente, a partir da média e do desvio padrão dos eventos foi aplicada a fórmula, conforme tabela 02 :

TABELA 02-Fórmulas para determinação dos níveis de intensidade de precipitação

\begin{tabular}{|c|c|}
\hline Normal & $\mathrm{P}<\underline{M}$ máx. \\
\hline Nível I & $M$ máx. $\leq \mathrm{P} \leq M$ máx. $+1 \sigma$ \\
\hline Nível II & $M$ máx. $+1 \sigma \leq \mathrm{P} \leq M$ máx. $+2 \sigma$ \\
\hline Nível III & $\bar{M}$ máx. $+2 \sigma \leq \mathrm{P} \leq \bar{M}$ máx. $+3 \sigma$ \\
\hline Nível IV & $M$ máx. $+3 \sigma \leq \mathrm{P}$ \\
\hline
\end{tabular}

Onde: $\underline{M}$ máx.: Média dos Máximos; $\sigma$ = Desvio Padrão; $\mathrm{P}=$ Evento pluviométrico. Adaptado de Monteiro e Zanella (2017).

\section{RESULTADOS E DISCUSSÃO}

\section{Os eventos extremos de precipitação e sua identificação na série histórica}

A partir da técnica dos Máximos de Precipitação foi possível identificar 214 eventos superiores ao percentil $95(45,6 \mathrm{~mm})$, para a aplicação da técnica, foram calculados os valores da média, que compreendeu o valor de $62,5 \mathrm{~mm}$, e o desvio padrão dos máximos, que foi de $17,3 \mathrm{~mm}$, dessa forma procedeu-se com a aplicação dos intervalos a partir do conjunto de dados (Tabela 03).

TABELA 03-Classes de intensidade dos eventos diários para Juiz de Fora- MG

\begin{tabular}{c|c|c}
\hline $\begin{array}{c}\text { Classes de } \\
\text { intensidade }\end{array}$ & Intervalos calculados & Frequência de eventos \\
\hline Normal & $45,6-62,5 \mathrm{~mm}$ & 135 \\
\hline Nível I & $62,6-79,8 \mathrm{~mm}$ & 47 \\
\hline Nível II & $79,9-97,1 \mathrm{~mm}$ & 7 \\
\hline Nível III & $97,2-114,2 \mathrm{~mm}$ & 5 \\
\hline Nível IV & $>114,2 \mathrm{~mm}$ & \\
\hline
\end{tabular}

Fonte: Organizado pelos autores.

Com relação aos eventos pluviométricos (Figura 05), observa-se que a grande maioria dos dados se encontram na classe dos eventos normais e que ocorrem de maneira recorrente ao longo da 
série, com 135 registros. Os níveis de intensidade I e II registraram 47 e 20 eventos respectivamente, e os eventos de intensidade III e IV, que superaram os $97,1 \mathrm{~mm}$ em $24 \mathrm{~h}$, foram registrados em 7 dias da série. Os eventos de intensidade IV, objeto de investigação do trabalho, ocorreram em 5 casos na série e superaram a marca de $114,2 \mathrm{~mm}$ em $24 \mathrm{~h}$.

\section{Os eventos extremos de intensidade IV:}

Os eventos extremos de intensidade IV, conforme já colocado, ocorreram em cinco (5) casos ao longo da série, sendo que todos foram registrados no período da estação chuvosa em Juiz de Fora, dois (2) no mês de Janeiro, um (1) em fevereiro, um (1) em março e um (1) em Novembro (Tabela 04).

De acordo com Oliveira (2016) o período chuvoso está associado à atuação dos sistemas frontais, linhas de instabilidade, bem como da atuação da Zona de Convergência do Atlântico Sul. Com relação aos eventos extremos, Cavalcanti (2012) revela que é comum a ocorrência de eventos extremos de precipitação no período de Outubro a Março associada à passagem de Sistemas Frontais ou a atuação da Zona de Convergência do Atlântico Sul (ZCAS).

TABELA 04- Características dos eventos pluviométricos de intensidade IV

\begin{tabular}{c|c}
\hline Data & $\begin{array}{c}\text { Evento pluviométrico } \\
(\mathrm{mm})\end{array}$ \\
\hline $17 / 01 / 1985$ & $122,4 \mathrm{~mm}$ \\
\hline $19 / 01 / 1993$ & $119,6 \mathrm{~mm}$ \\
\hline $12 / 02 / 1995$ & $137,5 \mathrm{~mm}$ \\
\hline $11 / 03 / 2001$ & $124,6 \mathrm{~mm}$ \\
\hline $12 / 11 / 2016$ & $125,0 \mathrm{~mm}$ \\
\hline \multicolumn{2}{|c}{. }
\end{tabular}

Fonte: Organizado pelos autores.

\section{Os eventos extremos e sua gênese: uma investigação a partir da circulação atmosférica}

Primeiramente é necessário destacar que a identificação dos sistemas atmosféricos atuantes durante os eventos investigados perpassa diferentes períodos, com diferentes possibilidades técnicas para a respectiva identificação, dessa forma, com o passar dos anos as possibilidades de investigação foram evoluindo fazendo com que os eventos mais recentes disponham de um arsenal maior de informações. Assim, os eventos serão apresentados de acordo com a própria sequência cronológica, a partir de 17/01/1985 ao evento de 12/11/2016. 


\section{O evento extremo de 17/01/1985}

Avaliando a sequência de cartas sinóticas é possível visualizar o avanço de uma Frente Fria que ocorre a partir do dia 09/01, esta frente a partir desse dia entra em uma fase estacionária, e partir do eixo dessa Frente Estacionária alinham dois campos de baixa pressão, que denotam a convergência de umidade Amazônica, uma vez que se orientam no sentido NW-SE, esse padrão se mantém até o dia 14/01, no dia 15/05 esse sistema estacionário avança para NE e cede espaço para outro sistema Frontal, que passa a atuar no dia 16/01, no dia 17/01 (data do evento extremo) novamente a Frente Fria assume um caráter estacionário e novamente se alinha a dois campos de Baixa Pressão que caracterizam a convergência de umidade no sentido NW-SE (Figura 05).

Figura 05- Sequência de cartas sinóticas para os dias 16-18 de Janeiro de 1985.

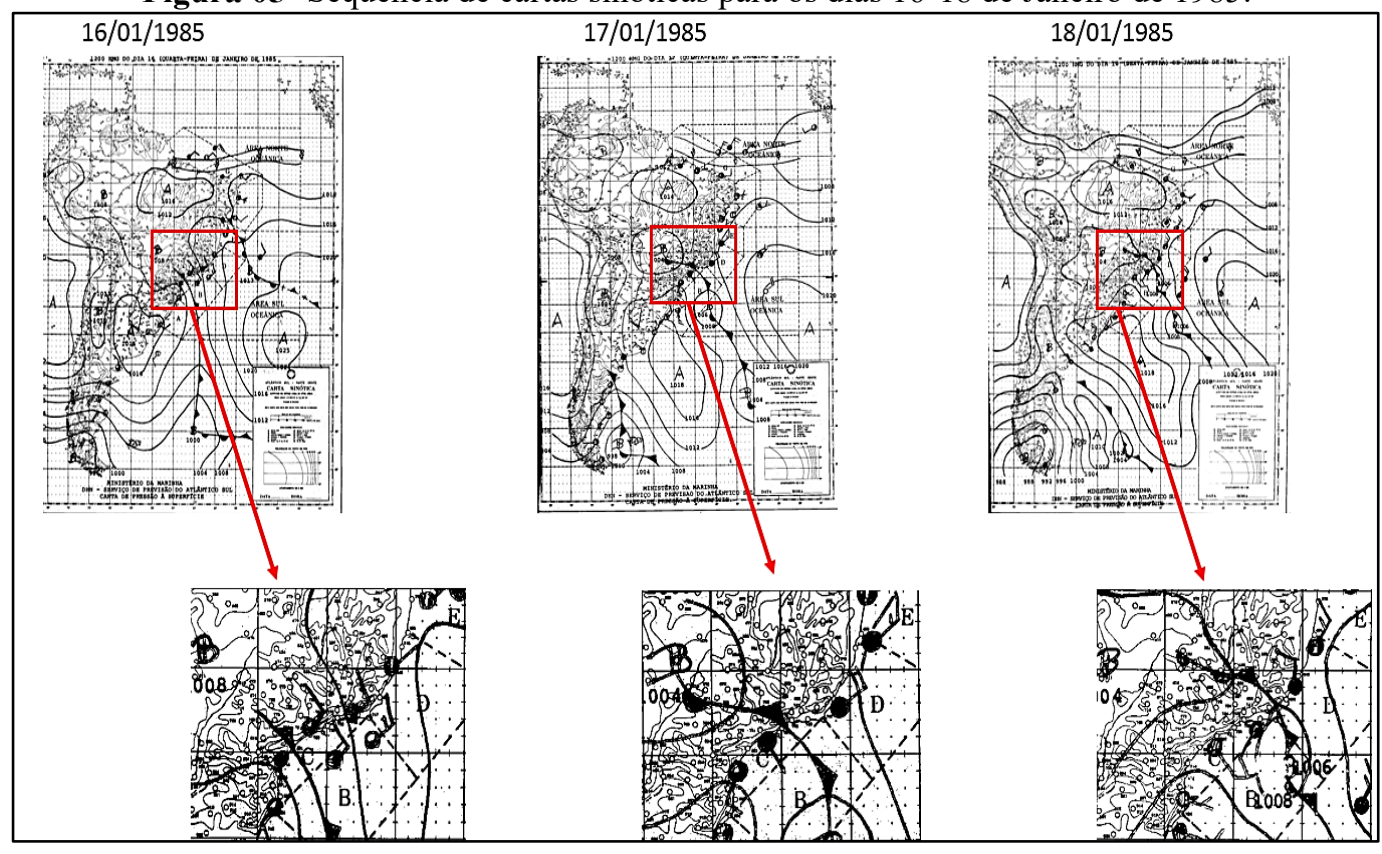

Fonte: Marinha do Brasil.

Dessa forma o evento pluviométrico esteve associado à passagem do Sistema Frontal que permitiu uma convergência de umidade Amazônica para a região Sudeste do Brasil. Na figura 06 é possível visualizar os totais pluviométricos estimados pelo CHIRPS para o período entre o dia $16 \mathrm{e}$ 20 deste Janeiro, revelando os maiores totais pluviométricos no eixo NW-SE entre a porção Norte do Brasil e o Sudeste, sendo que em Juiz de Fora atingiu 122,4 mm apenas no dia 17/01/1985. 
Figura 06-Espacialização da precipitação estimada pelo CHIRPS para 16-20 de Janeiro de 1985.

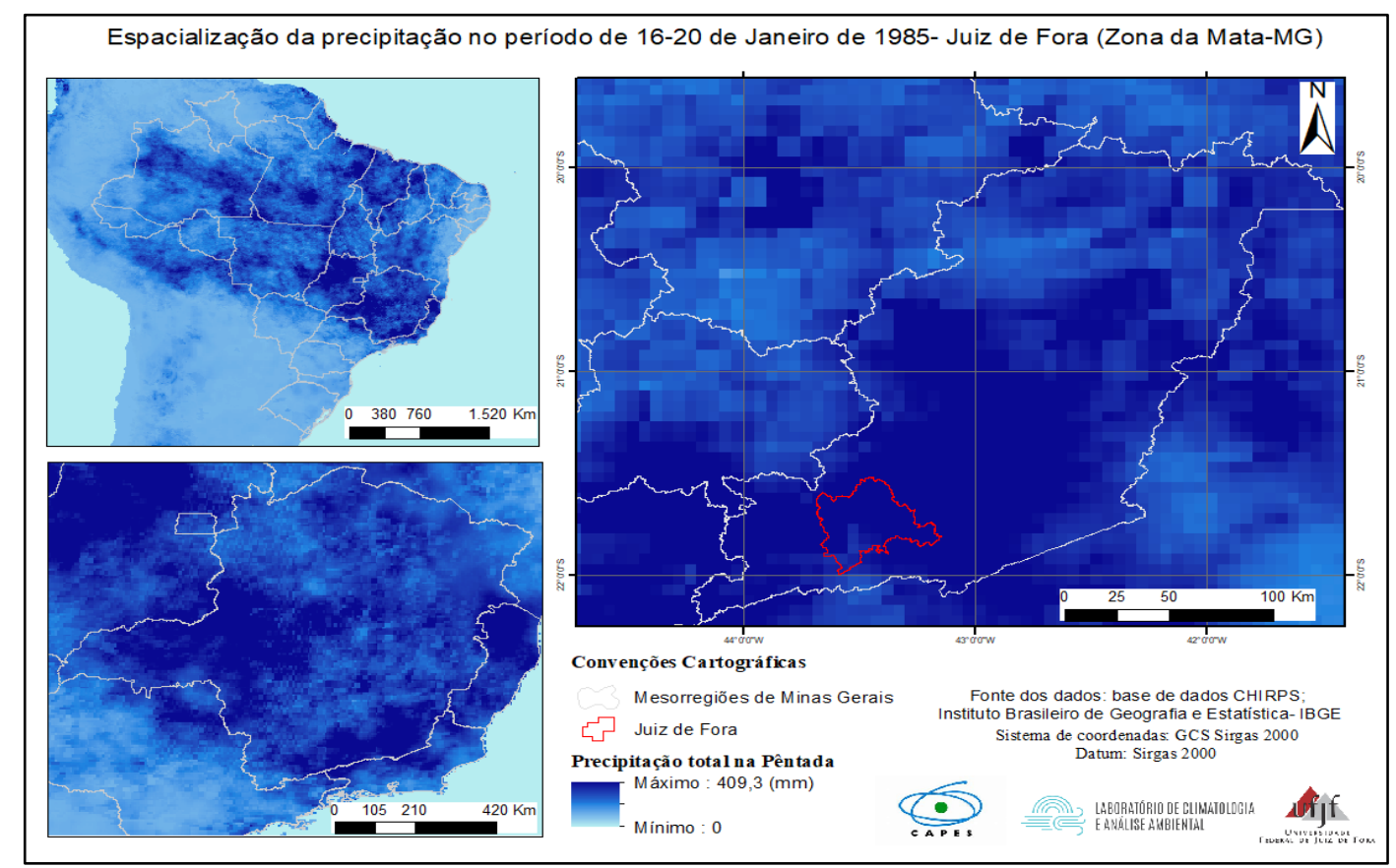

Fonte: Organizado pelos autores.

No evento de 17 de Janeiro de 1985, foram registrados 20 pontos de impactos na cidade. Dentre as ocorrências estiveram alagamentos e inundações, bem como deslizamentos e desabamentos (Figura 07). Os alagamentos foram registrados no Centro da cidade, além de inundações nas regiões Leste, Sul e Centro-Oeste da cidade. Além disso, os deslizamentos e desabamentos foram registrados principalmente nas regiões Sul, Leste e Sudeste da cidade.

Figura 07-Registros de deslizamentos e alagamentos em Juiz de Fora.

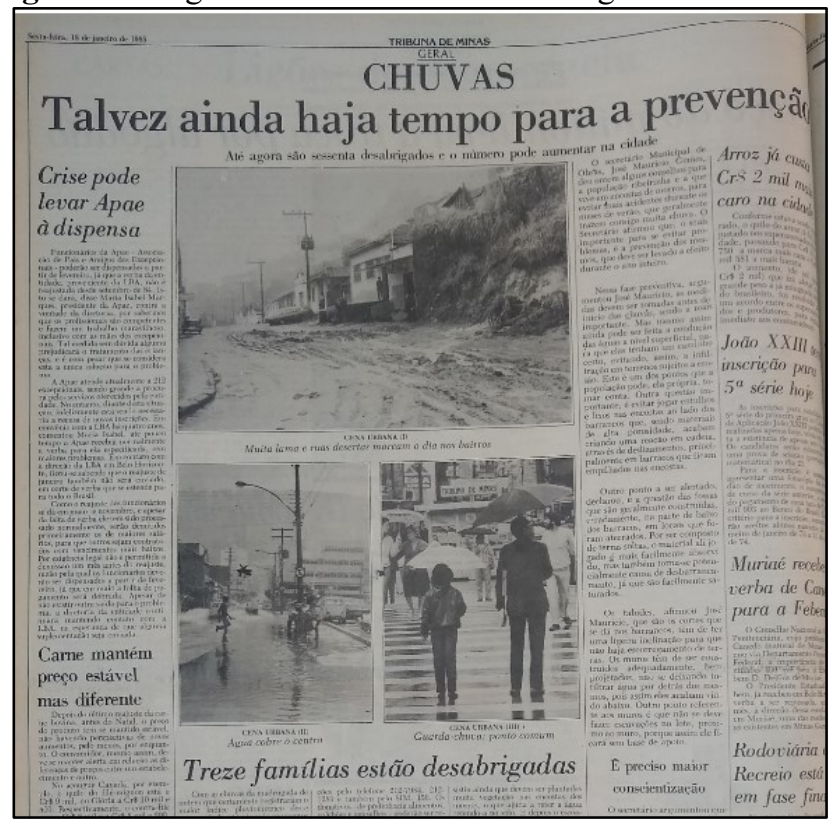

Fonte: Jornal Tribuna de Minas (18/01/1985, p. 6). 


\section{O evento extremo de 19/01/1993}

O evento extremo de Janeiro de 1993 esteve associado à passagem de um sistema frontal pelo litoral do Sudeste do Brasil, a partir do dia 16/01 uma Frente Fria inicia seu deslocamento em direção a NE, passando pelo litoral Brasileiro, sendo que no dia 17 ela atinge a porção sul do Brasil, e conecta a um sistema de baixa pressão no continente (Figura 08).

Infelizmente a carta do dia 18 de Janeiro não foi disponibilizada, no entanto no dia 19 o sistema frontal já avançara pelo litoral Brasileiro atingindo o estado do Espírito Santo, porém dois centros de baixa pressão se configuram, um na porção Centro- Norte de Minas Gerais e outro no Oeste do Estado de São Paulo denotando uma convergência de ventos.

Figura 08- Sequência de cartas sinóticas para os dias 17-20 de Janeiro de 1993

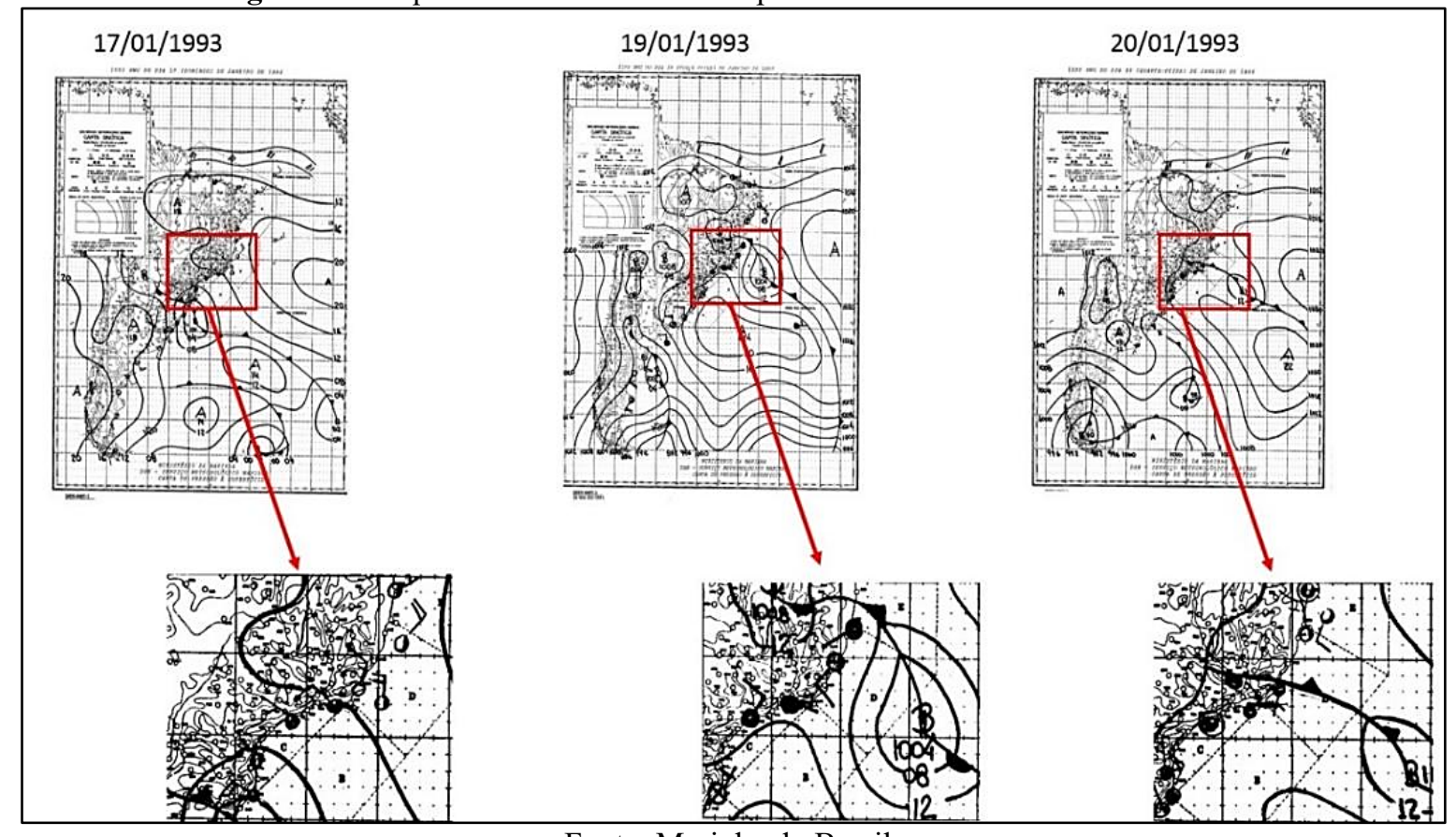

Fonte: Marinha do Brasil.

A estimativa de dados dos dados CHIRPS demonstra porções com os maiores totais pluviométricos distribuídos de maneira dispersa pelo estado de Minas Gerais, sendo que na Zona da Mata Mineira é possível observar um deles próximo à microrregião de Juiz de Fora, sendo que no dia 19/01/1993 choveu 119,6mm na cidade. Nesse caso é possível destacar que o evento esteve associado à passagem do Sistema Frontal que desencadeou a convergência de umidade para a Zona da Mata Mineira (Figura 09). 
Figura 09- Espacialização da precipitação estimada pelo CHIRPS para 16-20 de Janeiro de 1993.

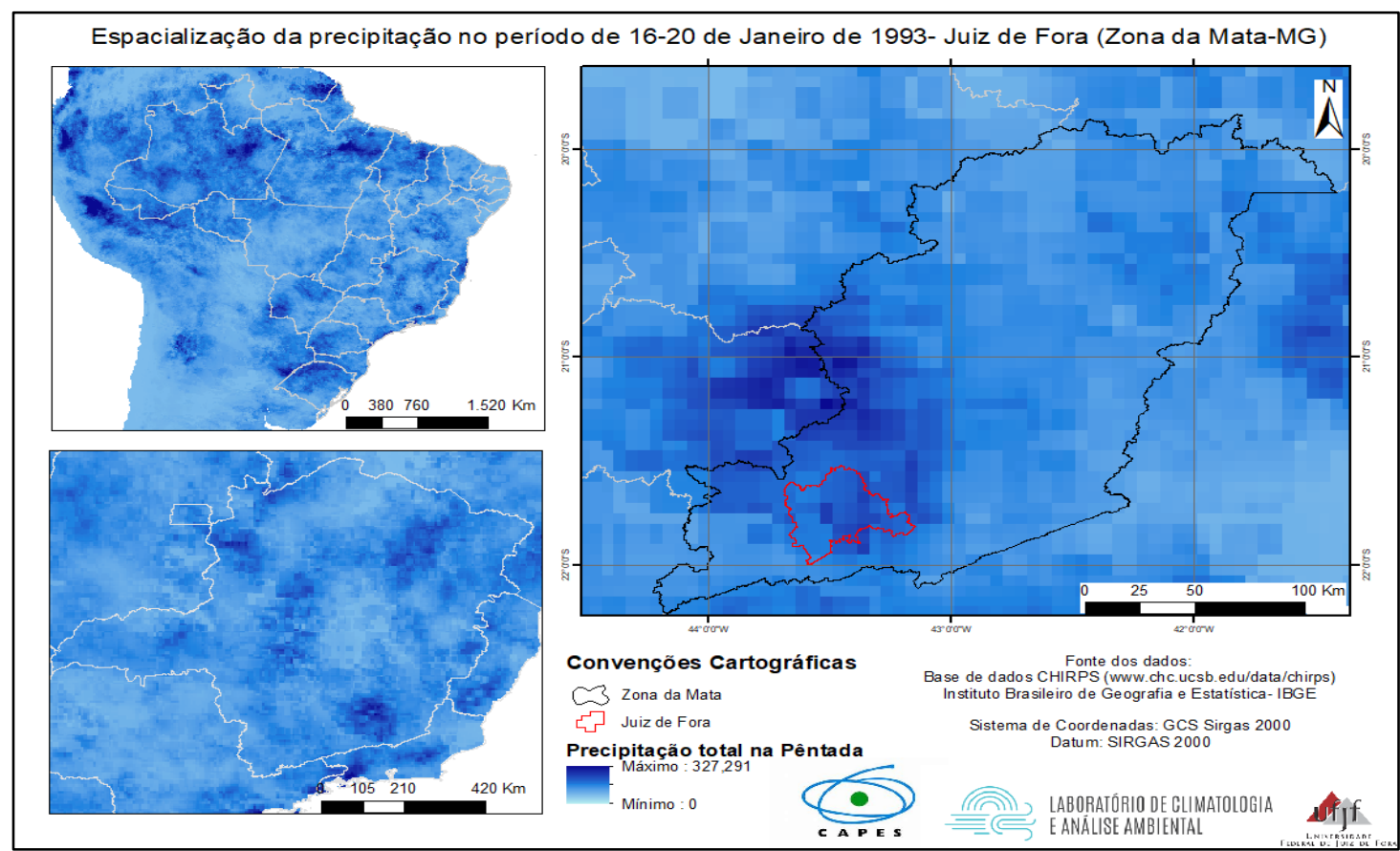

Fonte: Organizado pelos autores.

O evento de 19 de Janeiro de 1993 ocasionou a ocorrência de 7 pontos de impactos na cidade, sendo que dois deslizamentos ocorridos na Região Leste da cidade, nos bairros São Benedito e Grajaú (Figura 10) tiveram maior destaque na notícia. Além disso, alguns pontos de alagamento foram registrados na cidade.

Figura 10-Ocorrências de deslizamentos na cidade

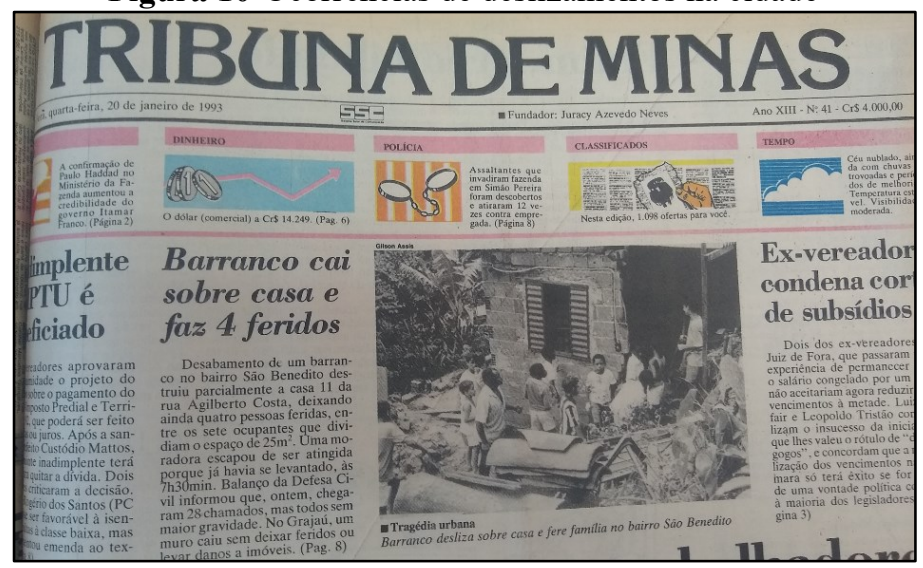

Fonte: Jornal Tribuna de Minas (20/01/1993, p. 1).

\section{O evento extremo de 12/02/1995}

O evento extremo de Janeiro de 1995 esteve associado também à passagem de um sistema frontal pelo litoral do Sudeste do Brasil, que assume um caráter estacionário a partir do dia 12 de 
Fevereiro, e dessa forma desencadeia o estabelecimento de dois centros de baixa pressão entre a região Sudeste e Centro-Oeste do Brasil, favorecendo o escoamento de umidade da região Amazônica (Figura 11).

Figura 11-Sequência de cartas sinóticas para os dias 11-13 de Fevereiro de 1995

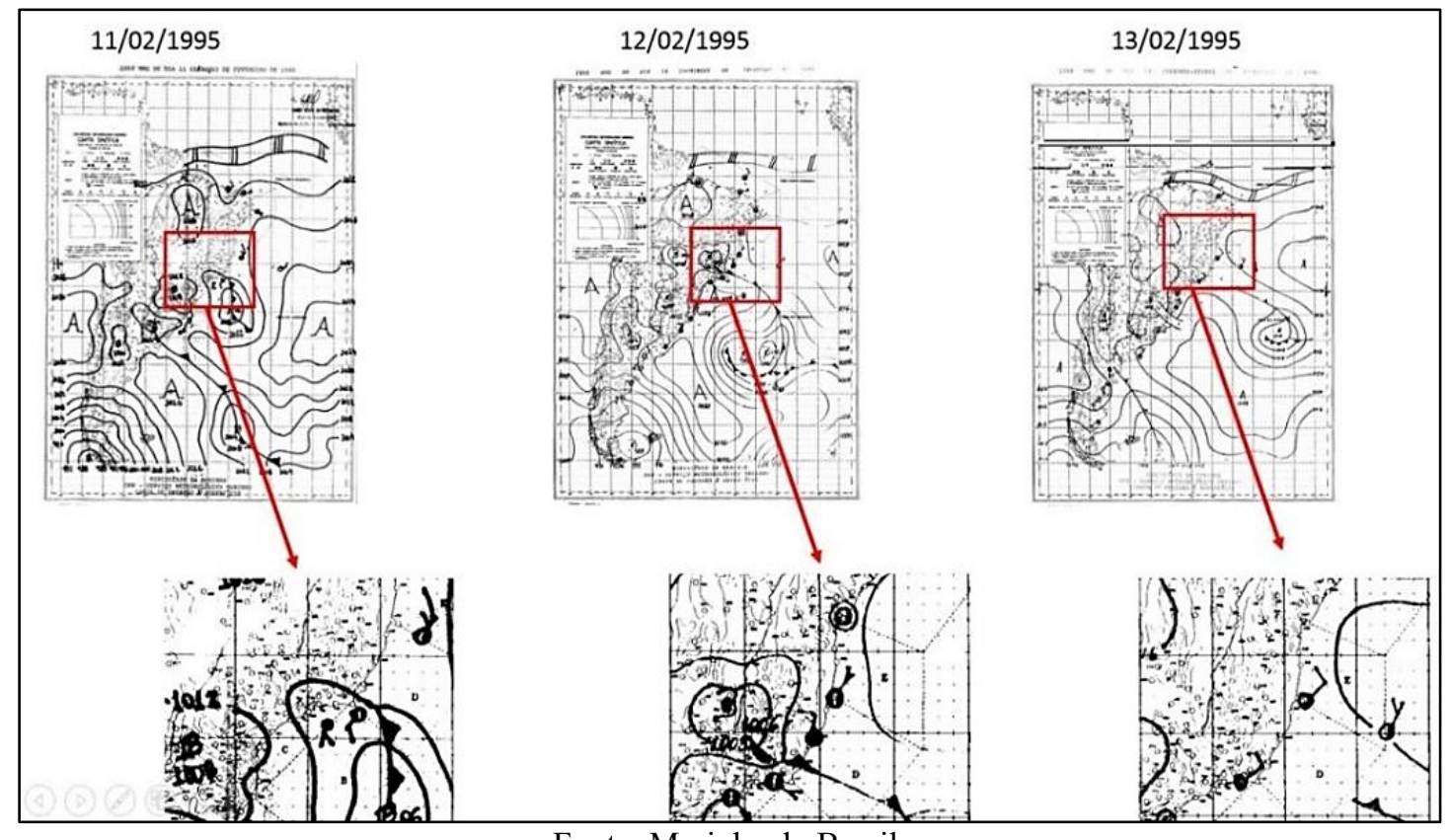

Fonte: Marinha do Brasil.

Figura 12-Espacialização da precipitação estimada pelo CHIRPS para 11-15 de Fevereiro de 1995.

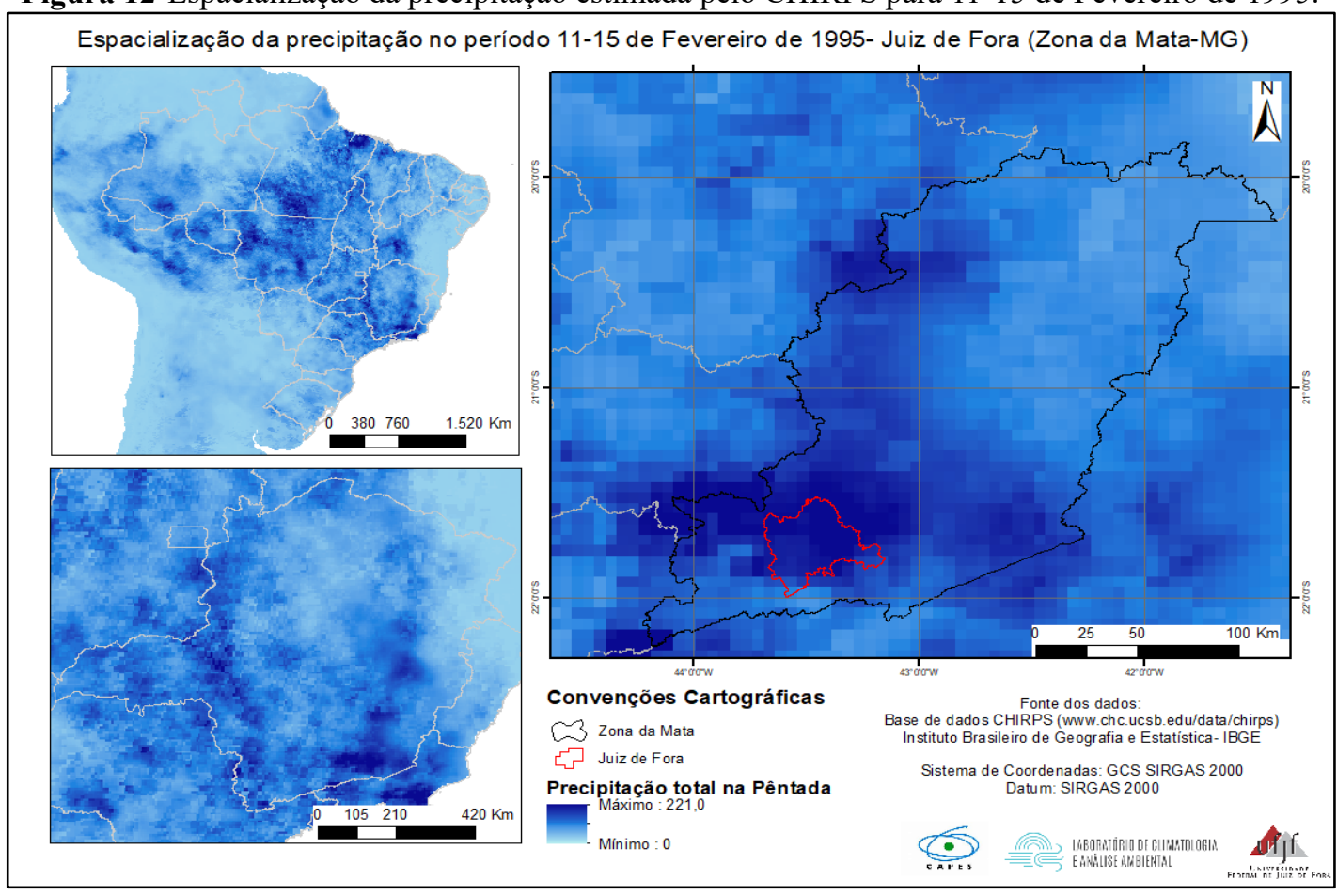

Fonte: Organizado pelos autores. 
Na figura 12 é possível visualizar o alinhamento de áreas com os maiores totais pluviométricos no sentido NW-SE característico do período do verão, associado à passagem dos sistemas frontais e que consequentemente se associam à umidade proveniente da região Norte do Brasil formando as Zonas de Convergência de Umidade- ZCOU e ou Zonas de Convergência do Atlântico Sul-ZCAS, que atualmente são representadas nas cartas sinóticas, diferentemente do período investigado. No dia 12/02/1995 choveu 137,5mm na cidade, sendo este o maior total pluviométrico diário registrado nos dados da estação climatológica do INMET.

O evento de 12 de Fevereiro de 1995 causou a ocorrência de 27 pontos de impactos na cidade, além de 5 óbitos nos bairros Furtado de Menezes e Vila Olavo Costa. As ocorrências se espalharam por toda a cidade, com diversos deslizamentos e pontos de alagamentos e inundação, como nos bairros Industrial e Manoel Honório (Figura 13).

Figura 13- Impactos na cidade, registrados em 12 de fevereiro de 1995

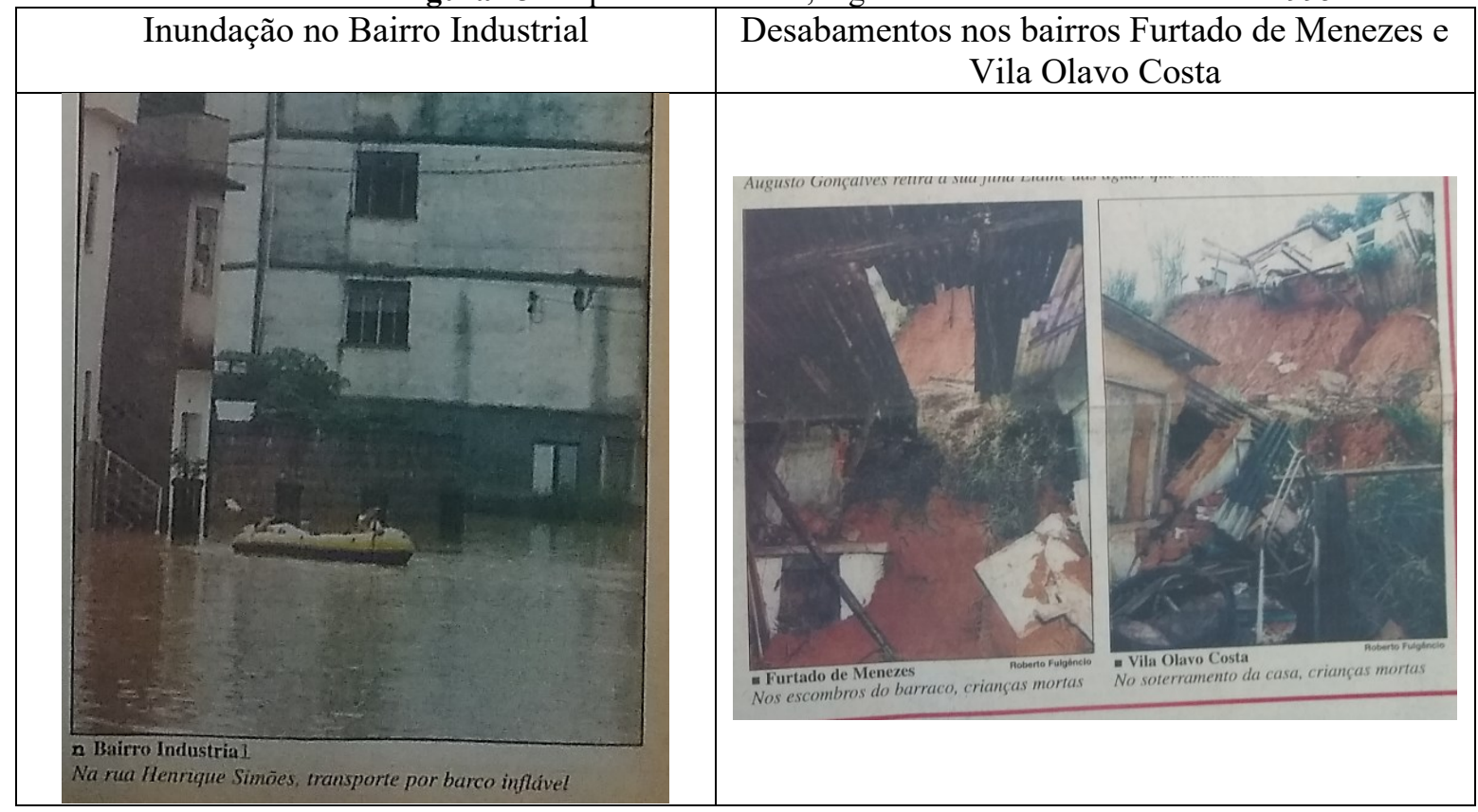

Fonte: Jornal Tribuna de Minas (14/02/1995, p. 1 e 11).

\section{O evento extremo de 11/03/2001}

O início do mês de Março de 2001 foi marcado pela passagem de um sistema Frontal no dia 07/03 que desencadeou uma convergência de umidade a partir da região Amazônica (Figura 14). Com isso, a partir do dia 09/03 uma sequência de centros de baixa pressão se estabeleceram no Brasil Sudeste, Culminando no evento de $124,6 \mathrm{~mm}$ registrado no dia 11 deste mês. 
Mais uma vez a configuração espacial com chuvas mais abundantes se estabeleceu em direção à região Sudeste do Brasil, podendo-se assim creditar o evento a uma Zona de Convergência de Umidade, pois não é possível precisar o período exato de atuação desse sistema, como pode ser visualizado na figura 15.

Figura 14- Sequência de cartas sinóticas para os dias 10-12 de Março de 2001.

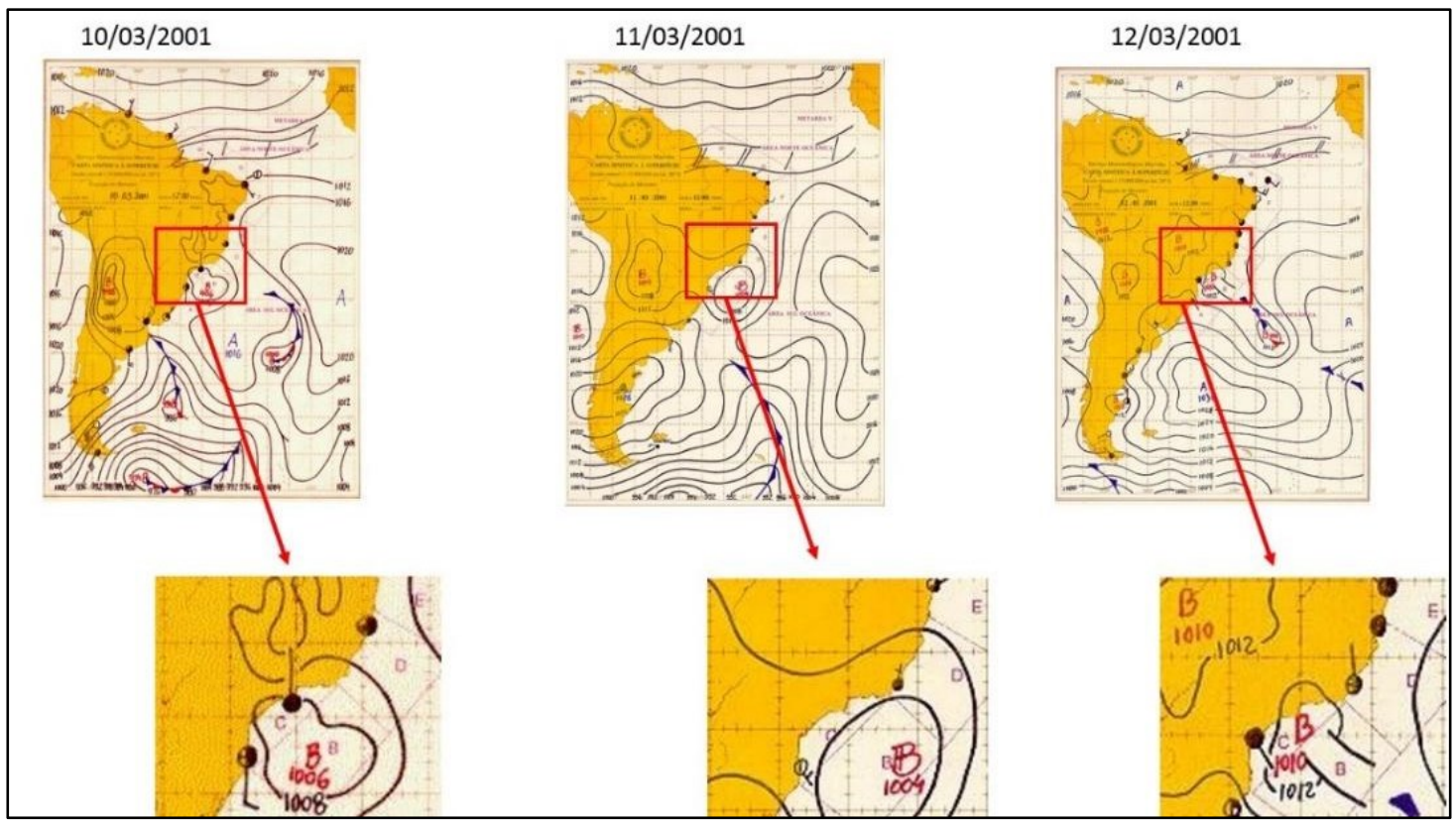

Fonte: Marinha do Brasil.

Figura 15- Espacialização da precipitação estimada pelo CHIRPS para 11-15 de Março de 2001

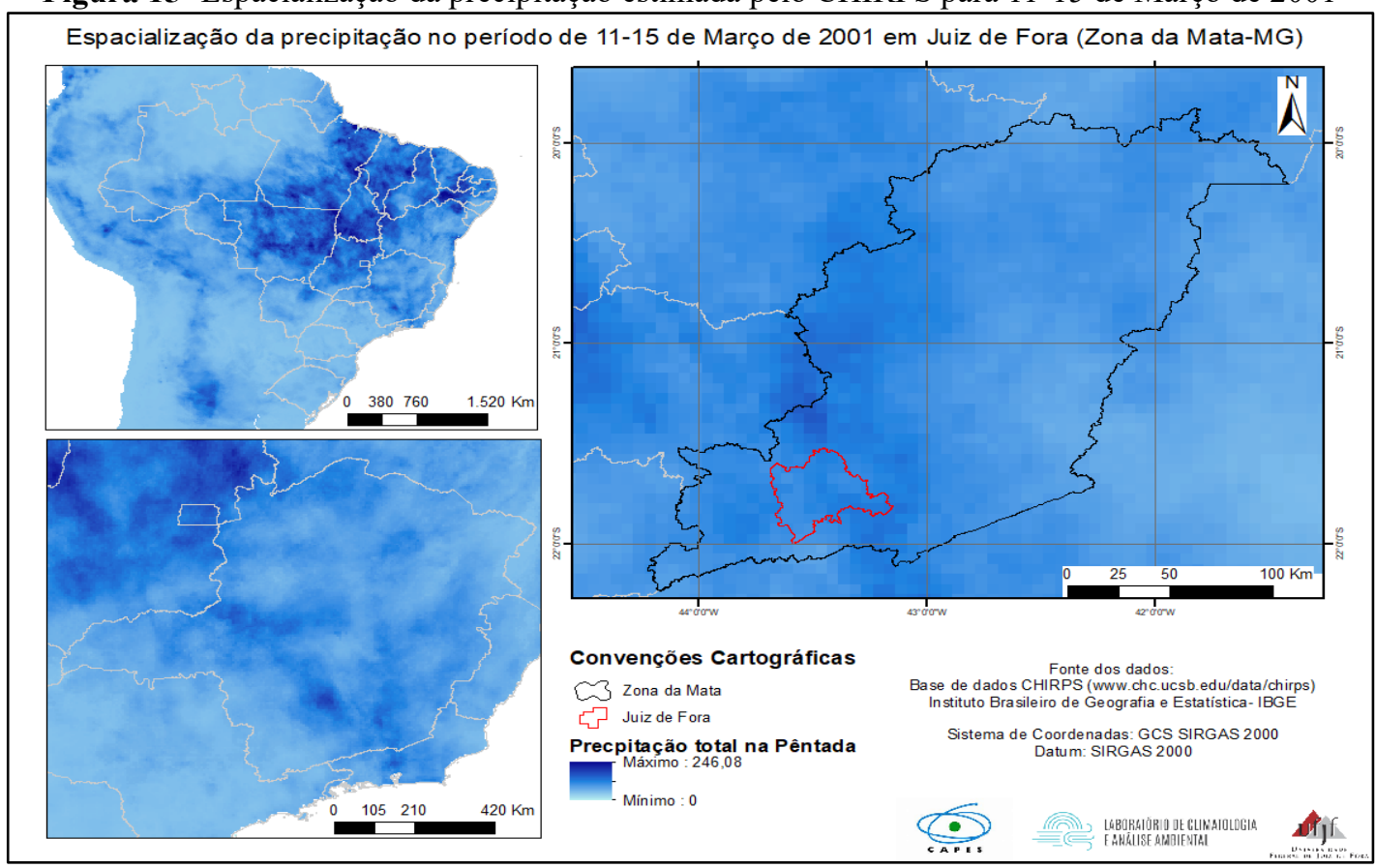

Fonte: Organizado pelos autores 
O evento de 11 de março de 2001 produziu 10 pontos de impactos na cidade, com ocorrências de alagamentos e inundação no Centro e no bairro Democrata, além de deslizamentos nos bairros Dom Bosco e Bairu. No Centro várias lojas do comércio foram atingidas ocasionando perdas de objetos. No bairro Democrata o córrego São Pedro inundou a rua Benjamim Guimarães (Figura 16).

Figura 16-Registro dos impactos nos bairros Dom Bosco, Democrata e Centro.

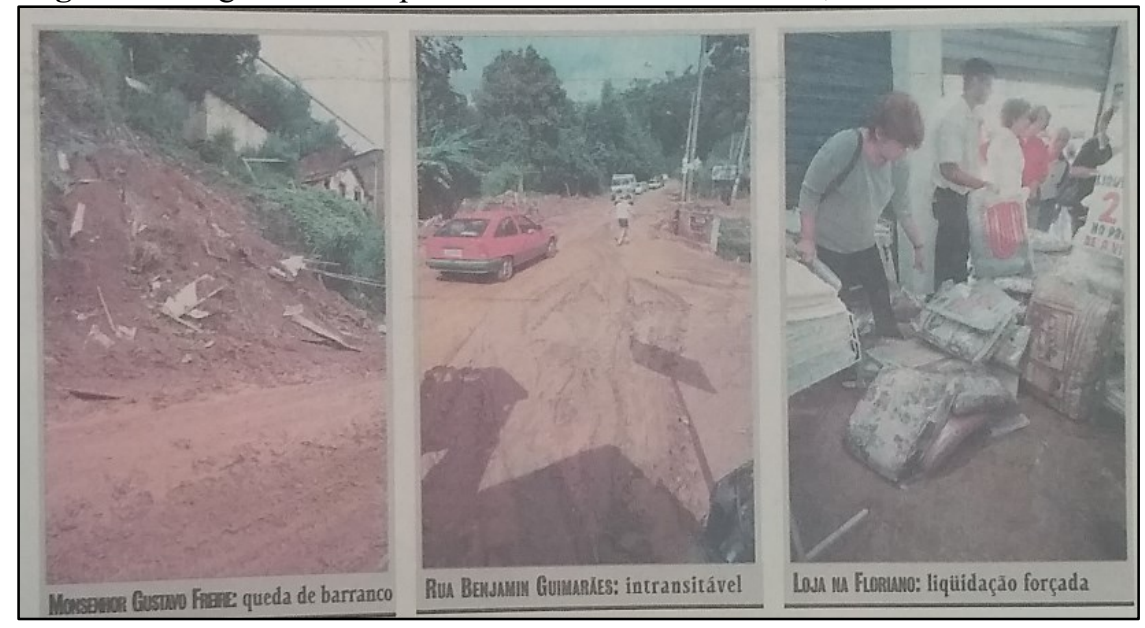

Fonte: Jornal Tribuna de Minas (13/03/2001, p.1; Caderno Cidade p.1).

\section{O evento extremo de 12/11/2016}

$\mathrm{Na}$ sequência dos sistemas atmosféricos é possível visualizar a passagem de um sistema frontal pelo litoral Brasileiro desencadeando a corriqueira convergência de umidade proveniente da Região Norte do Brasil (Figura 17) desencadeando os elevados totais pluviométricos na Zona da Mata mineira, principalmente na microrregião de Juiz de Fora, onde atingiu o total de $125 \mathrm{~mm}$. 
Figura 17- Sequência de cartas sinóticas para os dias 11-13 de Novembro de 2016.

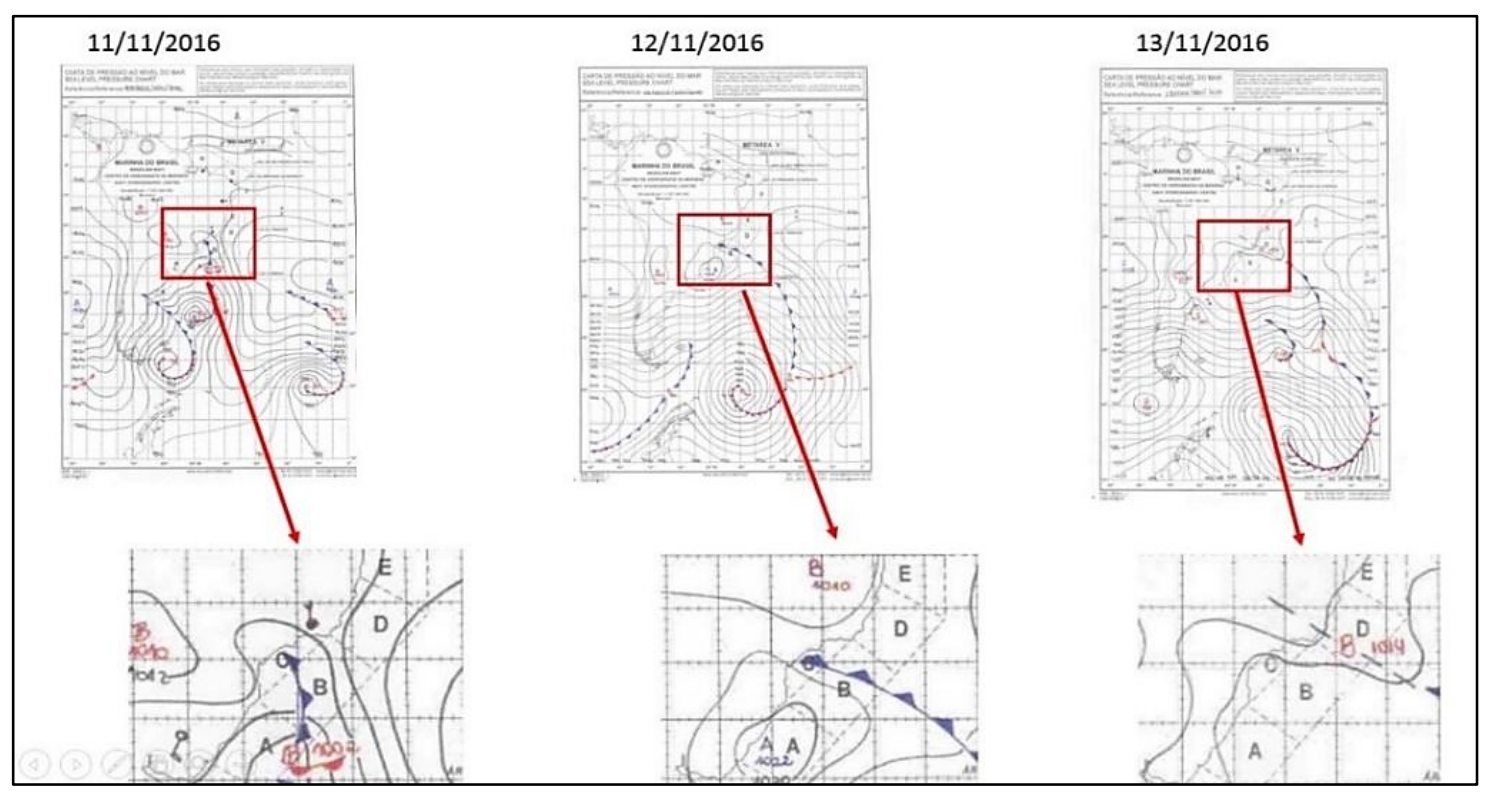

Fonte: Marinha do Brasil.

Na figura 18 é possível notar que a formação desse corredor de umidade provocou a ocorrência de elevados totais pluviométricos no eixo entre a região Norte e Centro-Oeste do Brasil e o Sudeste. Sendo que na porção da microrregião de Juiz de Fora visualiza-se que esta foi uma das áreas com os maiores totais ocorridos na Zona da Mata.

Figura 18- Espacialização da precipitação estimada pelo CHIRPS para 11-15 de Novembro de 2016.

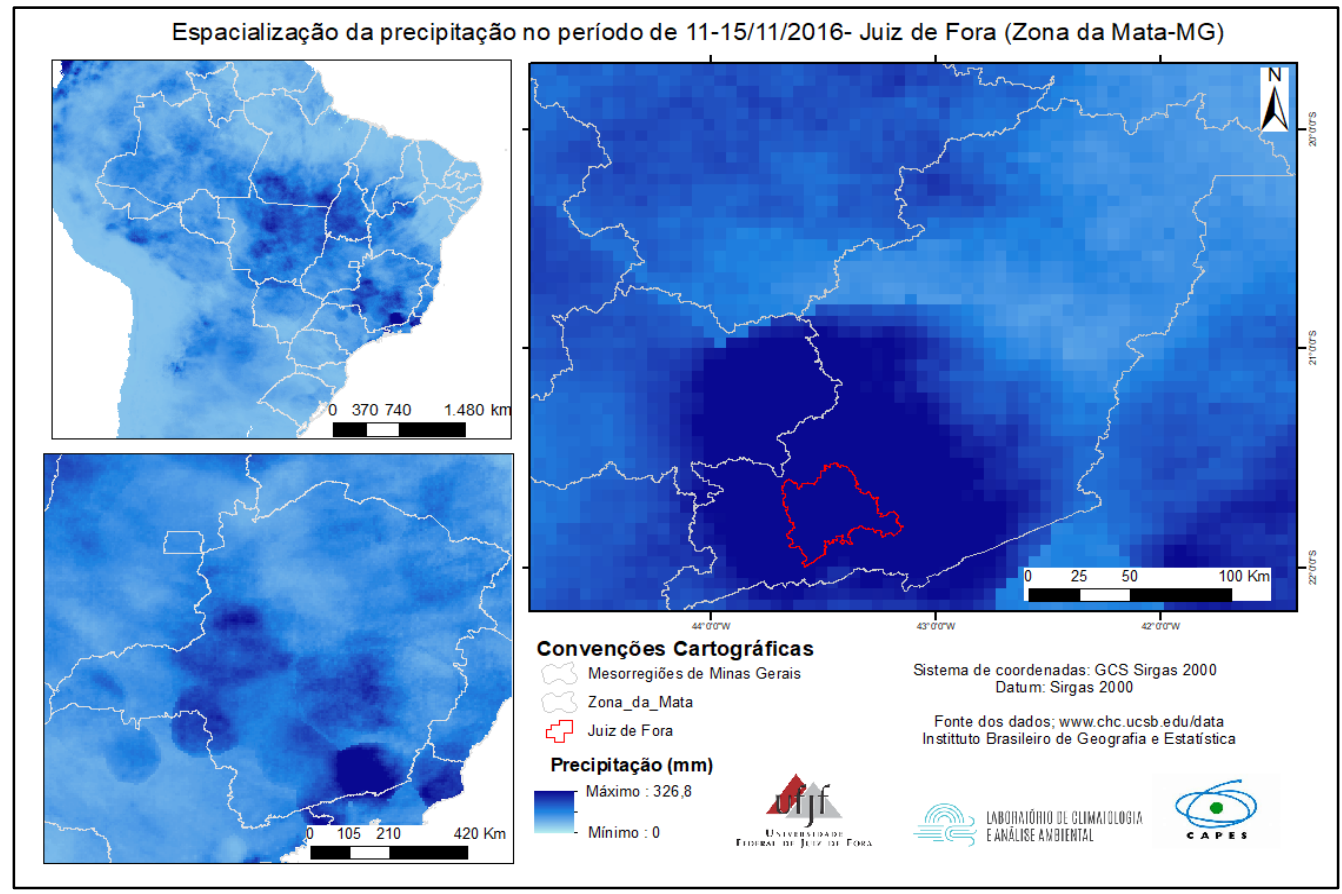

Fonte: Organizado pelos autores. 
O evento ocorrido em 12/11/2016 levou a ocorrência de 18 impactos na cidade de Juiz de Fora. Foram vários pontos de alagamento registrados na região Central da cidade, principalmente nos bairros Centro e Bom Pastor. Além disso, deslizamentos ocorreram nas regiões Norte, Oeste e Sul da cidade (Figura 19).

Figura 19- Deslizamento observado no bairro Nova Benfica, na região Norte da cidade.

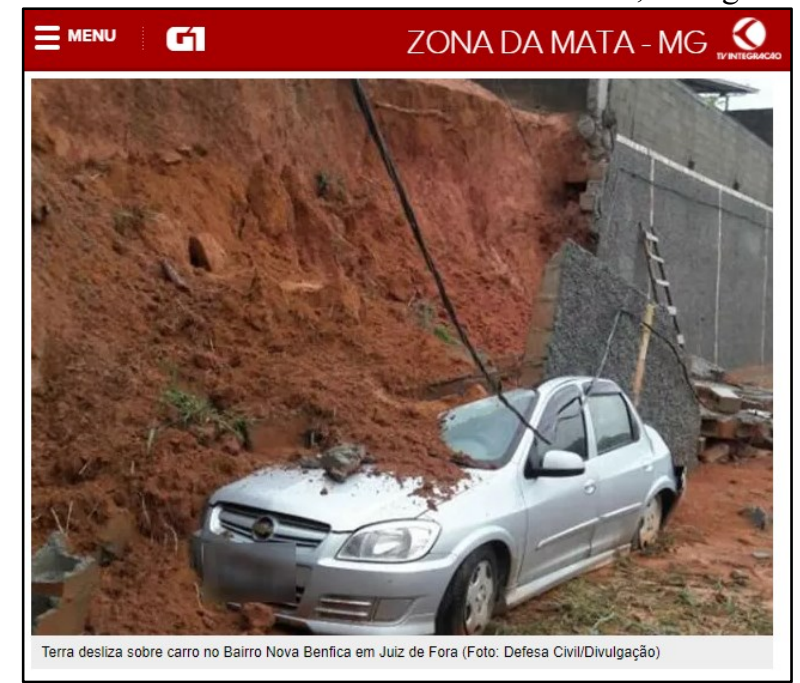

Fonte: Portal G1 Zona da Mata (13/11/2016).

A partir das figuras 06, 09, 12, 15 e 18, provenientes dos dados estimados CHIRPS, auxiliou na a identificação dos sistemas atmosféricos, como as convergências de umidade provenientes da região Amazônica, que não são facilmente visualizadas nas cartas sinóticas. Dos cinco eventos investigados, em quatro deles é viável notar nitidamente o incremento das chuvas na orientação NWSE no período destacado, apenas no recorte de Janeiro de 1993 esse processo não ficou explícito.

Com isso, destaca-se que os maiores eventos pluviométricos de Juiz de Fora estiveram associados à passagem de sistemas frontais e à convergência de umidade Amazônica. Durante os eventos de Zona de Convergência de Umidade (ZCOU) e ou Zona de Convergência do Atlântico Sul (ZCAS).

É necessário apontar que em todos esses casos os sistemas frontais atuaram dias antes ou de forma concomitante, gerando centros de baixa pressão no Sudeste do Brasil que podem ter atraído a convergência de umidade, através dos Jatos de Baixos Níveis (JBN) desencadeando os eventos extremos pluviométricos, concordando com a constatação feita por Cavalcanti (2012).

Exemplificando a partir dos eventos investigados é possível notar que os impactos das chuvas na cidade estão normalmente associados a ocorrência de movimentos de massa, inundações e alagamentos, eventos estes que deixam famílias desabrigadas, feridos e mortos, além de problemas na circulação viária da cidade (Figuras 07, 10, 13, 16 e 19). 
Destaca-se ainda que levando em conta os cinco eventos observados pode-se apontar que a região central da cidade foi citada diversas vezes pela ocorrência de alagamentos, bem como as inundações que ocorreram no bairro Industrial. Com relação aos deslizamentos estes foram mais numerosos nas regiões Leste, Sudeste e Norte.

Assim, com a crescente impermeabilização do solo, as alterações nos sistemas de drenagem e as construções em locais susceptíveis a movimentos de massa tem agravado os impactos associados às chuvas intensas, principalmente se entendermos a cidade, núcleo do sistema, e como produtora de espaços desiguais, direcionando as pessoas com menor poder econômico para as áreas menos desprovidas de condições de habitação, e mais susceptíveis aos impactos climáticos.

\section{CONSIDERAÇÕES FINAIS}

Os eventos investigados se localizam no período conhecido como estação chuvosa na monção Sul-americana, que vai de Outubro a Março, depreende-se disso que a dinâmica climática em Juiz de Fora apesentou os maiores totais pluviométricos localizados ao longo do semestre chuvoso.

Esse processo está associado à própria dinâmica das grandes células de circulação atmosférica, como célula de Hadley, pois no período de verão austral ela se desloca ao sul e provocando a convergência de umidade no Brasil Central e Sudeste, no período seco ela se desloca a Norte e o Anticiclone Semifixo do Atlântico Sul se posiciona próximo à porção ocidental do continente sulamericano, ou sobre o continente, provocando os períodos de maior estabilidade atmosférica.

As chuvas em Juiz de Fora estão muito associadas à passagem dos sistemas frontais, que provocam as precipitações por si só, mas também levam à convergência de umidade Amazônica, levando à formação das Zonas de Convergência do Atlântico Sul-ZCAS. Além disso, a própria condição de sítio da cidade, bem como a suscetibilidade à ocorrência de movimentos de massa e inundações, quando associados a eventos pluviométricos elevados denotam diversos impactos à população da cidade.

Com isso, conclui-se que quando determinado evento pluviométrico causa impactos na cidade de Juiz de Fora, é de fundamental importância levarmos em conta todas as escalas espaço-temporais inerentes ao sistema climático, extremamente complexo. Dentre os impactos registrados observa-se a ocorrência de inundações, alagamentos, bem como os deslizamentos e desabamentos.

Considerando os pressupostos de Monteiro $(1976$; 1999) e a necessidade de investigação em diferentes escalas, tentamos com este trabalho destacar as múltiplas interações e possibilidades de investigação que estão ligadas às precipitações intensas. No entanto, do ponto de vista geográfico o 
elemento fundamental perpassa o entendimento dos reflexos causados por estes eventos às sociedades humanas.

\section{AGRADECIMENTOS}

Agradecemos à CAPES pela bolsa de mestrado concedida ao primeiro autor deste trabalho.

\section{REFERÊNCIAS BIBLIOGRÁFICAS}

BORSATO, V. A dinâmica climática do Brasil e massas de ares. Curitiba-PR: CRV, 2016.

CAMPOS, T. L. O. B.; MOTA, M. A. S.; SANTOS, S. R. Q. Eventos extremos de precipitação em Belém-PA: uma revisão de notícias históricas de jornais. Revista Ambiente e Água. V. 10. N. 1. P. 182-194, 2015.

CAVALCANTI, I. F. A. Large scale and synoptic associated with extreme precipitation over South America: a review and case studies for the first decade the $21^{\text {st }}$ century. Atmospheric Research, 118, p. 27-40, 2012.

FUNK, C.; PETERSON, P.; LANDSFELD, M.; PEDREROS, D.; VERDIN, J.;SHUKLA, S; HUSAK, G.; ROWLAND, J.; HARRISON, L.; HOELL, A.;MICHAELSEN, J. The climate hazards infrared precipitation with stations-a new environmental record for monitoring extremes, Scientific data, v. 2, p. 150066, 2015.

GAN, M.; RODRIGUES, L. R.; RAO, V. B. Monção na América do Sul. In: CAVALCANTI, I.F.A.; FERREIRA, N.J.; DA SILVA, M.G.A.J.; SILVA DIAS, M.A.F. Tempo e Clima no Brasil. São Paulo: Oficina de Textos, 2009.

GERALDO, W. M. J. A reestruturação urbana pós-fordista de Juiz de Fora. Dissertação (Mestrado em Geografia), Universidade Federal Fluminense, Instituto de Geociências, Niterói, 271 f, 2014.

GONÇALVES, N. M. S. Impactos pluviais e desorganização do espaço urbano em Salvador-BA. Tese de Doutorado (em Geografia), Curso de Pós-Graduação em Geografia, Departamento de Geografia, Faculdade de Filosofia, Letras e Ciências Humanas, Universidade de São Paulo, 1992.

GOUDARD, G. Eventos naturais extremos e riscos hidrometeorológicos híbridos na bacia do Alto Iguaçu. Dissertação de Mestrado (em Geografia), Programa de Pós-Graduação em Geografia, Setor de Ciências da Terra, Universidade Federal do Paraná, 2019.

LOUREIRO, R. S.; SARAIVA, J. M.; SARAIVA, I.; SENNA, R. C.; FREDÓ, A. S. Estudo dos eventos extremos de precipitação ocorridos em 2009 no estado do Pará. Revista Brasileira de Meteorologia, v. 29, n. especial, p. 83-94, 2014.

MARENGO, J. A.; ALVES, L. M.; AMBRIZZI, T.; YOUNG, A.; BARRETO, N. J. C.; RAMOS, A. M. Trends in extreme rainfall and hydrogeometeorological disaster in the Metropolitan Area of São Paulo: a review. Annals of the New York Academy of Sciences. 2020.

MONTEIRO, C. A. F. Teoria e Clima Urbano. IG06- USP, 1976. (Série Teses e Monografias n. 25). MONTEIRO, C. A. F. Clima e excepcionalismo: conjecturas sobre o desempenho da atmosfera como fenômeno geográfico. Florianópolis: Editora da UFSC, 1991. 
MONTEIRO, C. A. F. O estudo geográfico do clima. Cadernos Geográficos, Departamento de Geografia, Centro de Filosofia e Ciências Humanas, Universidade Federal de Santa Catarina Florianópolis, 1999.

MONTEIRO, J. B. Desastres naturais no estado do Ceará: uma análise de episódios pluviométricos extremos. Tese de Doutorado (em Geografia), Programa de Pós-Graduação do Departamento de Geografia. Universidade Federal do Ceará- UFC, 2016.

MONTEIRO, J. B.; ZANELLA, M. E. A metodologia dos máximos de precipitação aplicada ao estudo de eventos extremos diários nos municípios de Crato, Fortaleza e Sobral- CE. Revista Geotextos, v. 13, n. 2, p. 135-159, 2017.

MONTEIRO, J. B.; ZANELLA, M. E. Eventos extremos no estado do Ceará: uma análise estatística dos episódios pluviométricos de março de 2019. Revista Geotextos, v. 15, n. 2, p. 149-173, 2019.

NIMER, E. Climatologia do Brasil. Rio de Janeiro: IBGE, 1979.

NUNES, L. H.; VICENTE, A. K.; CANDIDO, D. H. Clima da região Sudeste do Brasil. In: CAVALCANTI, I.F.A.; FERREIRA, N.J.; DA SILVA, M.G.A.J.; SILVA DIAS, M.A.F. Tempo e Clima no Brasil. São Paulo: Oficina de Textos, 2009.

OLIVEIRA, D. E. Participação dos sistemas atmosféricos na gênese e ritmos das chuvas na bacia hidrográfica do Rio Preto MG/RJ. Dissertação de mestrado (em geografia), Instituto de Ciências Humanas- ICH, Universidade Federal de Juiz de Fora, Juiz de Fora, 2016.

PAZ, C. M. V.; SANCHES, F. O.; FERREIRA, R. V. Chuvas em Uberaba: em estudo sobre a ocorrência de eventos extremos. Revista Entre- Lugar, v. 10 , nº 20, 2019.

PINHEIRO, G. M. Variabilidade têmporo-espacial da pluviosidade na bacia do Alto Iguaçu. Tese de Doutorado (em Geografia), Curso de Pós-Graduação em Geografia, Setor de Ciências da Terra, Universidade Federal do Paraná, 2016.

PRISTO, M. V. J.; DERECZYNSKI, C. P.; SOUZA, P. R.; MENEZES, W. F. Climatologia das chuvas extremas no município do Rio de Janeiro. Revista Brasileira de Meteorologia. V. 33. V. 2, p. 615630, 2018.

REBOITA, M. S.; KRUSCHE, N.; AMBRIZZI, T.; ROCHA, R. P. Entendendo o tempo e o clima na América do Sul. Revista Terra e didática. V. 8, p. 34-50, 2012.

REBOITA, M. S.; RODRIGUES, M.; SILVA, L. F.; ALVES, M. A. Aspectos climáticos do estado de Minas Gerais. Revista Brasileira de Climatologia, V. 17, Ano 11, p. 206-226, 2015.

RODRIGUES, A. S. R. Atuais dinâmicas socioespaciais: a habitação em Juiz de Fora-MG. Dissertação de mestrado (em Geografia), Programa de Pós Graduação em Geografia, Instituto de Geociências, Universidade Federal do Rio de Janeiro, 2005.

SILVA, C. B.; SILVA, M. E. S.; AMBRIZZI, T.; TOMMASELLI, J. T. G.; PATUCCI, N. N.; MATAVELI, G. A.V.; LIMA, B. M.; CORREA, W. C. Precipitação na América do Sul- dados obtidos por dados de estações automáticas e sistemas orbitais. Revista Brasileira de Climatologia. N.15, V. $25,2019$.

SOUZA, L. A. A produção desigual do espaço urbano de Juiz de Fora: a ocupação vila Barroso. Dissertação de mestrado (em Geografia), Programa de Pós Graduação em Geografia, Instituto de Ciências Humanas, Universidade Federal de Juiz de Fora, 2016.

STEPHENSON, D. B. Definition, diagnosis and origin of extreme weather and climate events. In: DIAZ, H.F e MURNANE, R. J (org.). Climate Extremes and Society, Cambridge University Press, p. 11-23, 2008. 
VALVERDE, M. C.; CARDOSO, A. O.; BRAMBILA, R. O padrão de chuvas na região do ABC Paulista: os extremos e seus impactos. Revista Brasileira de Climatologia, V. 22, Ano 14, p. 165 $187,2018$.

VICENTE, A. K. Eventos extremos de precipitação na Região Metropolitana de Campinas. Dissertação de Mestrado (em Geografia), Pós- Graduação em Geografia, Universidade Estadual de Campinas, Campinas, 2005.

WANDERLEI, L. S. A.; NOBREGA, R. S.; MOREIRA, A. B.; ANJOS, R. S.; ALMEIDA, C. A. P. As Chuvas na cidade do Recife: uma climatologia dos extremos. Revista Brasileira de Climatologia, V. 22, Ano 14, p. 149-164, 2018.

ZANELLA, M. E. Inundações urbanas em Curitiba/PR: Impactos, riscos e vulnerabilidade socioambiental no bairro Cajuru. Tese de Doutorado (em Geografia). Programa de Pós-Graduação em Meio Ambiente e Desenvolvimento. Universidade Federal do Paraná-UFPR, Curitiba, 2006. 